\title{
Studi Etnomatematika tentang Bagas Godang sebagai Unsur Budaya Mandailing di Sumatera Utara
}

\author{
Azhari Dewita1, Abdul Mujib²*, dan Hasratuddin Siregar ${ }^{3}$ \\ Sekolah Pascasarjana, Universitas Muslim Nusantara Al-Washliyah \\ Jalan Garu II No. 02 Medan, Sumatera Utara, 20147, Indonesia \\ 1dewipasaribu03@gmail.com \\ 2*mujib_umnaw@yahoo.co.id \\ Universitas Negeri Medan \\ Jalan Willem Iskandar Pasar V, Medan Estate, Sumatera Utara, Indonesia \\ ${ }^{3}$ siregarhasratuddin@yahoo.com
}

Artikel diterima: 12-08-2018, direvisi: 22-01-2019, diterbitkan: 31-01-2019

\begin{abstract}
Abstrak
Tujuan penelitian ini untuk mengetahui konsep (ide-ide) matematika yang terdapat pada rumah adat Mandailing yaitu Bagas Godang. Mandailing adalah salah satu suku Batak yang terletak di Kabupaten Tapanuli Selatan Sumatera Utara. Salah satu unsur budaya Mandailing adalah rumah adat Bagas Godang Sumatera Utara yang seharusnya menjadi perhatian pemerintah daerah setempat. Bagas Godang merupakan unsur budaya Mandailing yang dapat di jadikan media pembelajaran matematika sekolah, sehingga pembelajaran matematika dapat dimulai dari memperkenalkan budaya lokal seperti rumah adat budaya Mandailing atau Bagas Godang. Tulisan ini mengeksplorasi konsep-konsep matematika pada struktur dan ornamen rumah adat Bagas Godang. Pembahasan yang bersifat deskriptif memberi gambaran tentang ornamen rumah adat Bagas Godang lebih terperinci. Hasil eksplorasi dan analisis ornamen-ornamen Bagas Godang ditemukan adanya konsep matematika berupa konsep grup, geometri dan trasformasi geometri dan komposisinya.

Kata Kunci: mandailing, bagas godang, etnomatematika, konsep matematika, grup, geometri, transformasi geometri.
\end{abstract}

\section{Ethnomatematic Study of Bagas Godang as a Mandailing Culture Element in North Sumatera}

\begin{abstract}
The purpose of this study was to find out the concepts (ideas) of mathematics in the traditional Mandailing house, Bagas Godang. Mandailing is one of the Batak tribes located in South Tapanuli Regency, North Sumatra. One element of Mandailing culture is the traditional house of Bagas Godang, North Sumatra, which should be the concern of the local government. Bagas Godang is an element of Mandailing culture that can be used as a medium for school mathematics learning, so that mathematics learning can be started from introducing local culture such as the traditional Mandailing or Bagas Godang cultural houses. This research explores mathematical concepts in the structure and ornaments of the traditional Bagas Godang house. Descriptive discussion gives an overview of the traditional Bagas Godang house ornaments in more detail. Exploration and analysis of Bagas Godang ornaments found mathematical concepts such as group concepts, geometric concepts, and geometric transformations and their compositions.

Keyword: mandailing, bagas godang, etnomatematics, mathematical concepts, group, geometry, geometric transformations.
\end{abstract}




\section{Pendahuluan}

Kehadiran inovasi pembelajaran matematika sangat diperlukan sehingga pembelajaran matematika dapat menjadi lebih menyenangkan (Mujib, 2018). Oleh sebab itu dalam mengajarkan matematika, guru sebaiknya menggali pengetahuan matematika yang diperoleh dari kehidupan masyarakat di sekitar tempat tinggalnya. Hal-hal yang konkret dan berkaitan dengan pengalaman siswa dalam kehidupan seharihari dapat dijadikan sebagai sumber belajar yang menarik. Guru dapat mengaitkan materi matematika dengan aktivitas siswa dalam kehidupan sehari-hari dan kemudian secara perlahan mencari notasi formal/bentuk matematiknya (Afriansyah, 2012). Selain itu, guru juga diharapkan mampu mengembangkan pembelajaran yang memanfaatkan media atau alat bantu peraga atau memanfaatkan unsur budaya masyarakat yang ada. Sebagaimana pendapat Nugraha \& Sundayana (2014) bahwa pembelajaran dengan dibantu alat peraga lebih menyenangkan dan mudah dipahami. Salah satu aspek yang dapat dikembangkan untuk inovasi pembelajaran tersebut adalah budaya lokal setempat (kebudayaan daerah). Salah satu wujud pembelajaran berbasis budaya lokal tersebut adalah etnomatematika.

Etnomatematika merupakan kesadaran baru tentang pengenalan potensi diri masyarakat di bidang matematika, yaitu matematika di desain dalam kelompokkelompok budaya baik dari suku asli maupun orang-orang yang punya kepentingan dalam bidang matematika (Hasanuddin, 2017). Kajian etnomatematika masih minim dibicarakan dan masih awam pada sebahagian besar masyarakat, khususnya guru-guru matematika. Negara Indonesia sebagai negara yang beragam suku bangsa yang setiap suku masing-masing mempunyai budaya atau adat-istiadatnya sendiri, cukup punya potensi untuk memaksimalkan pengkajian dalam bidang budaya termasuk etnomatematika. Dengan perkembangan matematika dan dilatar belakangi kebutuhan hidup yang berbeda, maka setiap budaya dan sub budaya diharapkan dapat mengembangkan matematika dengan bekerja sama antara pihak terkait agar kebudayaan lokal dapat dilestarikan kepada generasi penerus bangsa.

Matematika sesungguhnya telah digunakan oleh setiap masyarakat dalam kehidupan sehari-hari. Matematika adalah bagian dari kebudayaan dan bagian dari kehidupan sehari-harinya (Murtiyasa, 2010). Oleh karena itu pembelajaran matematika di sekolah dewasa ini harus dikaitkan dengan konteks kehidupan sehari-hari siswa (Afriansyah, 2017), dengan model pembelajaran yang relevan dengan permasalahan sehari-hari. Pembelajaran yang mengaitkan dengan kehidupan sehari-hari adalah pembelajaran berbasis budaya. Ada empat komponen yang harus diperhatikan dalam pembelajaran berbasis budaya, yaitu substansi dan kompetensi bidang ilmu bidang studi, kebermaknaan dan proses pembelajaran, penilaian hasil belajar, serta peran budaya. Pembelajaran berbasis budaya lebih menekankan tercapainya pemahaman yang terpadu (integrated understanding) dari pada sekedar pemahaman mendalam (inert understanding) (Supriadri, 2013). Dengan menerapkan pembelajaran berbasis 
budaya, diharapkan siswa dapat memahami konsep dan mengurangi terjadinya miskonsepsi. Karena miskonsepsi selalu muncul dalam kegiatan belajar mengajar matematika (Mujib, 2017). Untuk itu, perlu sekali mengeksplorasi konsep matematika yang ada pada unsur budaya di Indonesia.

Keanekaragaman budaya Indonesia yang tersebar luas di beberapa kepulauan Nusantara memiliki nilai estetis yang tinggi, terutama dilihat dan diukur dari kadar seninya. Seni bangunan, seni tari, seni kerajinan, seni pahat, seni ukir, seni hias dan lain-lainnya. Seni bangunan tradisional merupakan ciri khas suatu suku bangsa yang ada di setiap daerah. Sumatera Utara termasuk penduduknya yang terdiri dari berbagai suku (etnis) diantaranya suku Batak, suku Jawa, suku Melayu dan lain sebagainya. Suku Batak termasuk suku yang banyak penghuninya di Sumatera Utara. Suku Batak terbagi lagi dalam beberapa suku Batak Karo, Batak Simalungun, batak Toba, Batak Mandailing (Kozok, 1999). Salah satu bangunan tradisional yang masih dijaga kelestariannya adalah bangunan rumah adat atau rumah yang diadatkan.

Suku Mandailing masih kental dengan adat istiadat. Salah satu bentuk budaya yang dapat langsung dilihat adalah rumah adat Bagas Godang. Dalam sistem kemasyarakatan Mandailing, daerah pemerintahan harus mempunyai rumah raja yaitu Bagas Godang dan Sopo Godang. Di daerah Mandailing, masyarakatnya mempunyai filsafat atau pandangan hidup mengatakan "hombar do adat dohot" ibadat artinya adat dan ibadat tidak dapat dipisahkan, adat tidak boleh bertentangan dengan agama Islam (Harahap, 2016).
Kebudayaan fisik arsitektur atau seni bangunan rumah adat Mandailing adalah bagian yang penting dari kebudayaan fisik masyarakat Mandailing. Terutama arsitektur atau seni bina bangunan adat berupa istana raja yang dinamakan Sopo Sio Mangodang atau Bagas Godang dan balai sidang adat yang dinamakan Sopo Sio Rancang Magodang atau Sopo Godang.

Bagas Godang merupakan nama rumah adat yang ada pada masyarakat suku Mandailing. Hasil survei peneliti yang dilakukan di daerah Muaratais kecamatan Batang Angkola Tapanuli Selatan, mulai dari anak kecil sampai orang dewasa sebagian besar tidak tahu mengenai Bagas Godang terlebih lagi tentang filosofi dan makna yang terkandung di dalamnya. Sehingga sangat perlu dilakukan pelestarian budaya khususnya budaya Bagas Godang. Dengan mengeksplorasi konsep - konsep matematika yang ada pada ornamen Bagas Godang, kita juga telah melakukan pelestarian budaya tersebut. Sebagaimana Lubis dkk (2018) yang telah mengeksplorasi konsep-konsep matematika pada alat musik Mandailing yaitu Gordang Sambilan, maka rumah adat bagas godang juga merupakan rumah adat yang tidak lepas dari konsep matematika. Berdasarkan uraian di atas, kajian ini bertujuan untuk mengungkapkan konsep-konsep matematika yang ada dalam rumah adat Mandailing Bagas Godang.

Dalam kehidupan bermasyarakat suku Mandailing mempunyai suatu kerajaan yang disebut Huta (Lubis, 2014). Suatu daerah kerajaan tentunya mempunyai seorang raja yang memimpin daerah tersebut dan bertempat tinggal di istana raja. Raja dalam pengertiannya seseorang 
yang sudah dinobatkan secara adat untuk memangku adat dimana karakter orang tersebut sudah bisa menjadi panutan atau jadi contoh teladan kepada masyarakat sekitarnya yang dalam bahasa Mandailingnya seperti yang dituturkan pemangku adat Bagas Godang Janji Mauli yaitu: "Jonjong jadi tudosan juguk jadi tiruan" yang artinya semua tingkah laku dan gerak geriknya dari ujung rambut ke ujung kaki menjadi panutan bagi masyarakatnya. Terdapat juga istilah "madung malo manyurat malo mamasa majo tangis so malo martata" yang artinya orang yang bisa membaca baik yang tersurat apalagi yang tersirat dan orang yang penuh pengalaman dan berwawasan yang luas dan tahu penderitaan sebelum tahu kebahagiaan. Orang yang tahu penderitaan yang bisa memahami rakyatnya tentang kehidupan. Raja pada suku Mandailing dikenal dengan sebutan Hatobangon ni Luhat atau Huta yang artinya orang yang dituakan di kampung tersebut. Gelar ini diabadikan kepada seseorang karena paham mengenai adat, mempunyai pengalaman yang luas dan rela mengabdikan dirinya untuk masyarakat (Kholidah, 2017).

Bagaimana layaknya seorang raja, dalam hal ini raja adat tentu mempunyai satu kediaman (singgasana), yaitu Bagas Godang dan Sopo Godang. Bagas Godang seperti yang ditunjukkan pada Gambar 1, merupakan bangunan arsitektur yang digunakan sebagai tempat kediaman raja, sementara itu Sopo Godang digunakan sebagai balai pertemuan. Rumah adat Bagas Godang berfungsi sebagai tempat tinggal atau kediaman raja adat sebagai pemimpin huta. Apabila sebuah huta atau kampung telah diresmikan sesuai dengan ketentuan adat, huta itu kemudian menjadi bona bulu. Ciri-ciri huta yang menjadi bona bulu adalah jika dikampung tersebut sudah dinobatkan seorang raja dan mempunyai tempat tinggal yaitu Bagas Godang Seperti Bagas Godang di daerah lain ada juga mempunyai ciri yang berbeda. Seperti ditanamnya pohon beringin dan berfungsi sebagai pembatas daerah atau benteng pertahanan kampung tersebut.

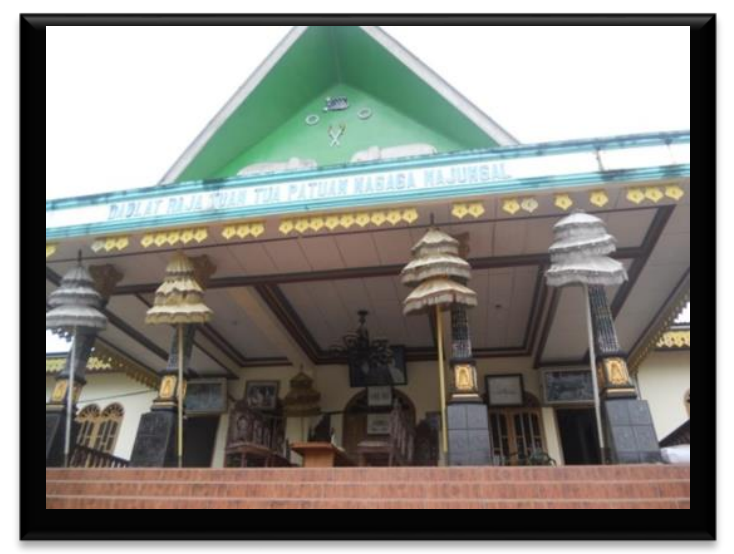

Gambar 1. Rumah Adat Bagas Godang Janji Mauli.

Di samping sebagai pembatas juga tanaman tersebut merupakan benteng pertahanan serangan musuh baik yang nyata ataupun tidak nyata (Kholilah 2017). Dalam masyarakat Mandailing yang sudah menjadi bona bulu harus mempunyai rumah adat Bagas Godang agar kegiatan kemasyarakatan

mempunyai kesekretariatan dan kegiatan tersebut terordiner dengan baik. Bangunan adat lainnya di Mandailing adalah Sopo Godang (lihat Gambar 2). Sopo Godang adalah sebuah bangunan yang berbentuk empat persegi panjang (Kholilah, 2017). Bangunan ini menyerupai bentuk Bagas Godang tetapi dalam ukuran yang lebih kecil, terbuka dan tidak memiliki dinding. Sopo Godang ini seperangkat dengan Bagas Godang dan letaknya berdampingan dengan Bagas 
Godang. Sebagai balai pertemuan dan memiliki fungsi yang lebih luas dibandingkan Bagas Godang, Sopo Godang digunakan sebagai tempat berbagai aktivitas seperti musyawarah adat, balai sidang pengadilan, pentas seni, tempat belajar adat, hukum, belajar kerajinan tangan serta ilmu yang lainnya.

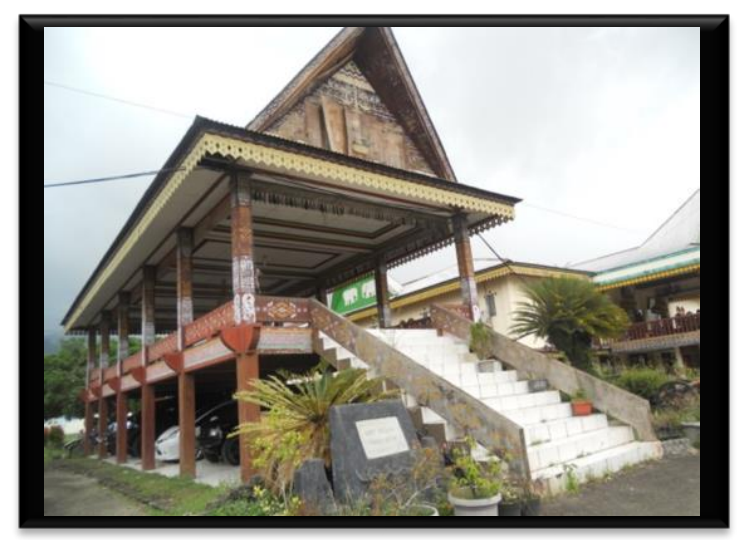

Gambar 2. Sopo Godang Janji Mauli.

Kedua bangunan adat tersebut bukan hanya penting bagi masyarakat Mandailing dari segi penggunaan praktisnya saja. Tetapi juga dari keberadaannya sebagai lambang status untuk menunjukkan kehormatan, kemuliaan dan kebesaran kelompok masyarakat atau komunitas di tempat kedua bangunan itu berada. Jika di satu tempat terdapat bangunan Bagas Godang dan Sopo Godang, itu menandakan bahwa tempat itu merupakan pusat pemerintahan huta atau banua, yang sekaligus berarti bahwa di tempat itu telah diakui berdirinya satu kerajaan dengan pemerintahan yang otonom (nasution \& pandapotan, 2005).

Bentuk dan struktur rumah adat Mandailing Bagas Godang Janji Mauli terdiri dari dua lantai permanen Pada rumah adat Mandailing Bagas Godang Janji Mauli bentuk panggung, Di lantai dua bagian teras terdapat empat tiang (hotang na opat) yaitu: Patik, uhum, ugari dan ujarujaran. Patik artinya ketetapan adat yang mutlak yang tidak bisa diubah. Uhum adalah sanksi bagi yang melanggar adat. Ugari adalah pengalaman manusia dalam kehidupan sementara ujar-ujaran melambangkan dalam agama dan adat harus bisa berdampingan. Bentuk tiang pada rumah raja (Bagas Godang) janji mauli sudah dimodifikasi dengan perpaduan bangun segi delapan, tabung. Bersebelahan dengan tiang terdapat bendera adat berwarna putih dan kuning. Bendera ini digunakan dalam acara adat.

Struktur bagian atas merupakan struktur atap, balok-balok atap dan penutup atap. Pada bagian ini terdapat bindu matogamatogu atau tutup ari dihiasi dengan ornamen tiga warna (putih, merah dan hitam) yang erat kaitannya dengan tata cara kehidupan Mandailing. Setiap bagian dari ornamen tersebut mengandung makna. Atap rumah raja memiliki tutup ari (bidang segitiga pada atap) pada tiap sisi, yaitu 4 (empat) buah tutup ari yang dilengkapi dengan ornamen dan ditambah satu buah pada bagian atap tangga. Dan bidang tutup ari dibagi atas sembilan bagian yang diberi hiasan dan memiliki makna tersendiri.

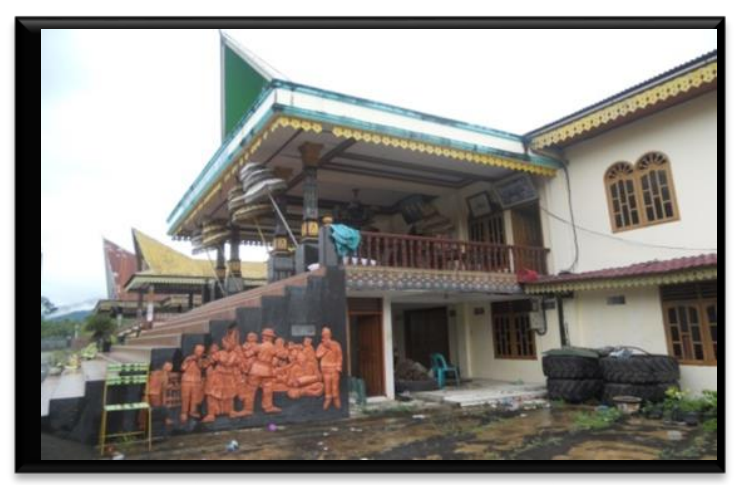

Gambar 3. Gelanggang Janji Mauli. 


\section{Metode}

Tujuan utama penelitian ini yaitu untuk mengeksplorasi konsep matematika yang ada pada rumah adat Bagas Godang suku Mandailing Sumatera Utara. Oleh karena itu penelitian ini menggunakan metode kualitatif deskriptif dengan tahapan terdiri dari:

1. Mengidentifikasi berbagai unsur etnomatematika

2. Menetapkan informan

3. Menggali informasi melalui wawancara dan observasi lapangan

4. Membuat catatan etnografis

5. Mengajukan pertanyaan deskriptif

6. Membuat kesimpulan melalui triangulasi data.

\section{Hasil dan Pembahasan}

Atap rumah raja memiliki tutup ari (bidang segitiga pada atap) pada tiap sisi, yaitu 4 (empat) buah tutup ari yang dilengkapi dengan ornamen dan ditambah satu buah pada bagian atap tangga. Seperti yang ditunjukkan pada gambar 4. Pada bagian atas tutup ari terdapat tiga cabang yang diberi nama marsalapsap pandenggani yang menggambarkan tiga sifat mulia yaitu : parbinegean, marparnidaan, dan marpangarohai, yang artinya 1) bagus dalam penglihatan maksudnya selalu menggunakan cara pandang yang positif karena kalau seseorang berpandangan positif tentu setiap apa pun dalam fenomena kehidupan ini tentu selalu mencari apa makna yang ada didalamnya, 2) Bagus dalam pendengaran artinya peka dalam berita maksudnya kapan berita suka cita kapan berita duka cita dan setiap mendengarkan apa pun harus ada saringan atau filter mana yang harus didengarkan mana yang harus di abaikan, 3) Bersih hatinya, artinya orang yang bersih hatinya tentu jauh dari sifat-sifat penyakit hati yang ada hanya ikhlas dalam berbuat dan bekerja tanpa pamrih. Dan bidang tutup ari dibagi atas sembilan bagian yang diberi hiasan dan memiliki makna tersendiri. Ornamen yang diterangkan pada tutup ari Bagas Godang dan Sopo Godang berupa garis-garis geometris (garis lurus) kecuali yang menggambarkan benda-benda alam, seperti matahari, bulan, dan bintang, serta bunga. Ornamen -ornamen (bolang) yang berfungsi sebagai simbol atau lambang. Simbol atau lambang itu memiliki makna makna yang sangat mendalam bagi masyarakat suku Mandailing.

Di dalamnya terkandung nilai-nilai, gagasan-gagasan, konsep-konsep, normanorma dan kaidah-kaidah, hukum dan ketentuan adat istiadat yang menjadi landasan dan pegangan dalam mengarungi bahtera kehidupan bermasyarakat.

Dilihat motif dari sudut ornamen yang ada pada rumah adat Mandailing Bagas Godang dalam Nasution (2011) telah menjelaskan nilai-nilai filosofis, nama ornamen, serta geometri bidang apa saja yang membangun ornamen bagas gondang sebagai berikut:

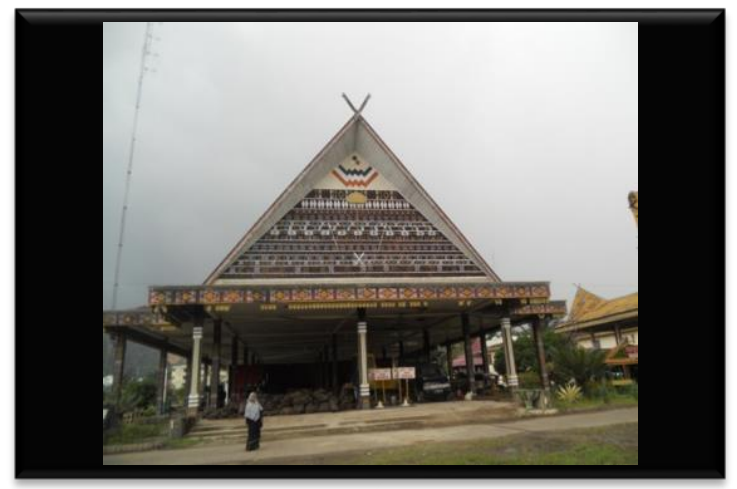

Gambar 4. Tutup Ari Bagas Godang. 
Tabel 1.

Filosofi Makna Ornamen pada Tutup Ari Bagas Godang

\begin{tabular}{|c|c|c|c|}
\hline $\begin{array}{l}\text { Konsep } \\
\text { Matematika }\end{array}$ & Bentuk Ornament & $\begin{array}{c}\text { Nama } \\
\text { Ornament }\end{array}$ & Filosofi \\
\hline $\begin{array}{l}\text { Geometri, } \\
\text { garis lurus, } \\
\text { dan simetris. }\end{array}$ & & $\begin{array}{l}\text { garis-garis } \\
\text { tegak lurus } \\
\text { (bona } \\
\text { bulu) }\end{array}$ & $\begin{array}{l}\text { di tempat tersebut berdiri satu kerajaan yang } \\
\text { sarana prasarananya lengkap antara lain : } \\
\text { unsur-unsur dalian natolu, (mora, kahanggi, } \\
\text { dan anak boru), raja pamusuk, Namora } \\
\text { Natoras, Ulubalang, Bayo-bayo Nagodang, } \\
\text { Datu dan Sibaso. }\end{array}$ \\
\hline $\begin{array}{l}\text { Geometri, } \\
\text { segitiga dan } \\
\text { simetris }\end{array}$ & & $\begin{array}{l}\text { Bindu atau } \\
\text { rusuk } \\
\text { robung }\end{array}$ & $\begin{array}{l}\text { System sosial Dalian natolu (tiga tunggu } \\
\text { sejarangan) atau adat markoum sisolkot } \\
\text { (adat berkaum kerabat) yang dianut oleh } \\
\text { masyarakat setempat. }\end{array}$ \\
\hline $\begin{array}{l}\text { Geometri, } \\
\text { segitiga, } \\
\text { pencerminan, } \\
\text { simetris kiri } \\
\text { dan kanan. }\end{array}$ & 罢A & $\begin{array}{l}\text { Burangir } \\
\text { eropik }\end{array}$ & $\begin{array}{l}\text { Fungsi raja dan namora Natoras, segala } \\
\text { sesuatu perihal, baik itu menyangkut } \\
\text { pelaksanaan upacara adat dan ritual harus } \\
\text { terlebih dahulu meminta pertambangan dan } \\
\text { ijin kepada raja dan namora na toras }\end{array}$ \\
\hline $\begin{array}{l}\text { Geometri, } \\
\text { pencerminan, } \\
\text { simetris kiri } \\
\text { dan kanan }\end{array}$ & & $\begin{array}{l}\text { Bintang } \mathrm{Na} \\
\text { Toaras }\end{array}$ & $\begin{array}{l}\text { pendiri huta. Artinya, Huta tersebut didirikan } \\
\text { oleh Natoras yang sekaligus berkedudukan } \\
\text { sebagai pimpinan pemerintahan dan } \\
\text { pimpinan adat yang dilengkapi dengan } \\
\text { hulubalang, Bayo-bayo nagodang, datu, dan } \\
\text { Sibaso }\end{array}$ \\
\hline $\begin{array}{l}\text { Geometri, } \\
\text { simetris kiri } \\
\text { dan kanan }\end{array}$ & & Rudang & $\begin{array}{l}\text { suatu huta yang sempurna, Artinya huta } \\
\text { tersebut lengkap dengan segala atribut } \\
\text { kebesaran adatnya seperti pakaian adat, } \\
\text { uning-uninga, senjata dan lain sebagainya. }\end{array}$ \\
\hline $\begin{array}{l}\text { Geometri, } \\
\text { segitiga dan } \\
\text { simetris }\end{array}$ & & $\begin{array}{l}\text { Bintang na } \\
\text { toras }\end{array}$ & $\begin{array}{l}\text { Pendiri huta. Huta tersebut didirikan oleh } \\
\text { natoras yang sekaligus berkedudukan } \\
\text { sebagai pimpinan pemerintahan dan } \\
\text { pimpinan adat yang dilengkapi oleh hulu } \\
\text { baling, bayo-bayo nagodang, datu dan sibaso }\end{array}$ \\
\hline $\begin{array}{l}\text { Geometri dan } \\
\text { simetris }\end{array}$ & & Raga-raga & $\begin{array}{l}\text { Keteraturan dan keharmonisan hidup } \\
\text { bersama, artinya hubungan kekerabatan } \\
\text { sangat erat dan berlangsung secara harmonis } \\
\text { dengan terjadinya hubungan perkawinan } \\
\text { antar marga, baik sesama warga huta } \\
\text { maupun orang yang berasal dari huta lain. }\end{array}$ \\
\hline $\begin{array}{l}\text { Geometri, } \\
\text { pencerminan } \\
\text { dan simetris } \\
\text { kiri dan } \\
\text { kanan }\end{array}$ & & $\begin{array}{l}\text { Sancang } \\
\text { Duri }\end{array}$ & $\begin{array}{l}\text { suatu kejadian yang tak terduga.Artnya, } \\
\text { Seseorang datang ke suatu huta dan ia } \\
\text { langsung ke sopo godang, maka Namora } \\
\text { Natoras wajib memberinya makan selama ia } \\
\text { berada dihuta itu dan apabila ia } \\
\text { meninggalkan huta harus diberi bekal } \\
\text { makana }\end{array}$ \\
\hline
\end{tabular}

Mosharafa: Jumal Pendidikan Matematika

Volume 8, Nomor 1, Januari 2019

Copyright $\odot 2019$ Mosharafa: Jurnal Pendidikan Matematika 
Geometri, segitiga, belah ketupat dan simetris kiri dan kanan.

Disisi lain dari sudut ornamen yang ada pada rumah adat Mandailing Bagas Godang terdapat konsep-konsep matematika dan nilai filosofis masyarakat Mandailing. Berdasarkan ornamenornamen tutup ari bagas godang, di sini akan di eksplorasi konsep matematika yang ada pada ornamen bona bulu, bindu, dan burangir eropik.

\section{A. Bona Bulu}

Bona bulu memiliki nilai filosofi bahwa di tempat tersebut berdiri satu kerajaan yang sarana prasarananya lengkap antara lain: unsur-unsur dalian natolu, (mora, kahanggi, dan anak boru), raja pamusuk, namora natoras, ulubalang, bayo-bayo nagodang, datu dan sibaso.

Secara konsep matematis, ornament bona bulu dapat di eksplorasi menggunakan konsep geometri kepatuhan masyarakat terhadap adat istiadat Artinya, dalam setiap huta telah ada ketentuan mengenai adat Marraja, adat Marmora, Markahanngi, Maranakboru, dan adat Naposo Nauli Bulung.

transformasi. Berdasarkan gambar 5, $\overrightarrow{A B}$ adalah vektor pada motif dasar bona bulu dan $P$ adalah titik pada motif tersebut. Misalkan $T(P)$ adalah translasi titik $P$ oleh vector $\overrightarrow{A B}, T^{-1}(P)$ adalah translasi titik $P$ oleh translasi $\overrightarrow{B A}$, dan $T^{n}(P)=P^{n}$ komposisi tanslasi $T$ terhadap titik $P$ sebanyak $n$ kali dan $P^{n}$ merupakan bayang titik $P$ oleh komposisi translasi $T^{n}$, maka himpunan

$\left\{\ldots T^{-2}(P), T^{-1}(P), I(P), T(P), T^{2}(P), T^{3}(P), \ldots\right\}$ merupakan sebuah grup siklis yang mengekspresikan secara matematis dari ornamen bona bulu. Oleh karena itu, terdapat beberapa konsep matematika yang ada pada proses pembentukan ornamen bona bulu diantaranya konsep translasi, komposisi fungsi translasi, vektor. Selain itu terdapat juga bentuk bangun datar persegi dan persegi panjang.

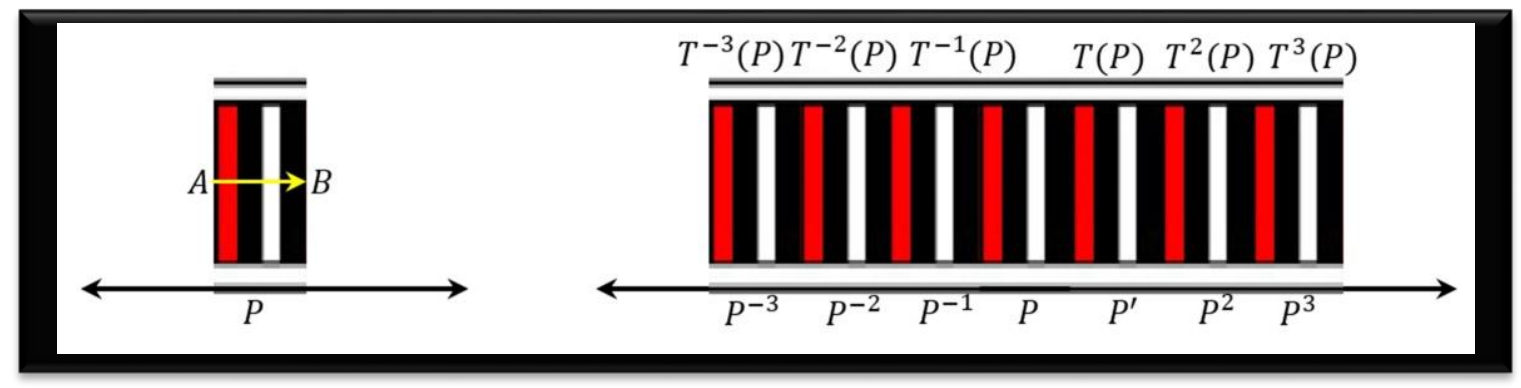

Gambar 5. Motif dasar Bona Bulu dan Proses Konstruksinya 


\section{B. Bindu atau Rusuk Robung}

Dalam menjawab rumusan masalah dan pertanyaan penelitian, hasil penelitian harus disimpulkan secara eksplisit. Penafsiran terhadap temuan dilakukan dengan menggunakan logika dan teoriteori yang ada. Temuan berupa kenyataan di lapangan diintegrasikan/ dikaitkan dengan hasil-hasil penelitian sebelum Bindu atau Rusuk Robung berarti system sosial Dalian Natolu (tiga tunggu sejarangan) atau adat markoum sisolkot (adat berkaum kerabat) yang dianut oleh masyarakat setempat.

Proses konstruksi ornamen Bindu secara konsep matematis dapat ditunjukkan seperti pada gambar 6 . Berdasarkan gambar 6a, misalkan titik $C$ adalah titik yang berada di sudut kanan bawah motif dasar rusuk robung, dan garis $l$ tegak lurus dengan garis sumbu $x$ dan melalui titik $C$, maka dengan merefleksikan motif dasar terhadap garis $l$ diperoleh motif pembangun dari ornament rusuk robung (lihat gambar 7b). Selanjutnya, kita dapat mengonstruksi ornamen bindu berdasarkan motif pembangun. Berdasarkan gambar $7 \mathrm{~b}$ dan 7c, diketahui vektor $\overrightarrow{D E}$ dan titik $Q$ pada motif pembangun Bindu. Misalkan $\tau(Q)$ adalah translasi titik $Q$ oleh vector $\overrightarrow{D E}$, maka himpunan $\left\{\ldots, \tau^{-2}, \tau^{-1}, i, \tau, \tau^{2}, \ldots\right\}$ adalah ekspresi matematis dari ornament bindu atau rusuk robung.

Oleh karena itu, pada ornamen bindu atau rusuk robung, kita dapatkan beberapa konsep matematis seperti refleksi garis, translasi, dan komposisi fungsi translasi.

Selain itu terdapat beberapa unsur geometri bidang seperti segitiga, jajargenjang, dan trapesium. Konsepkonsep ini dapat dikembangkan dalam bentuk pembelajaran di dalam kelas.

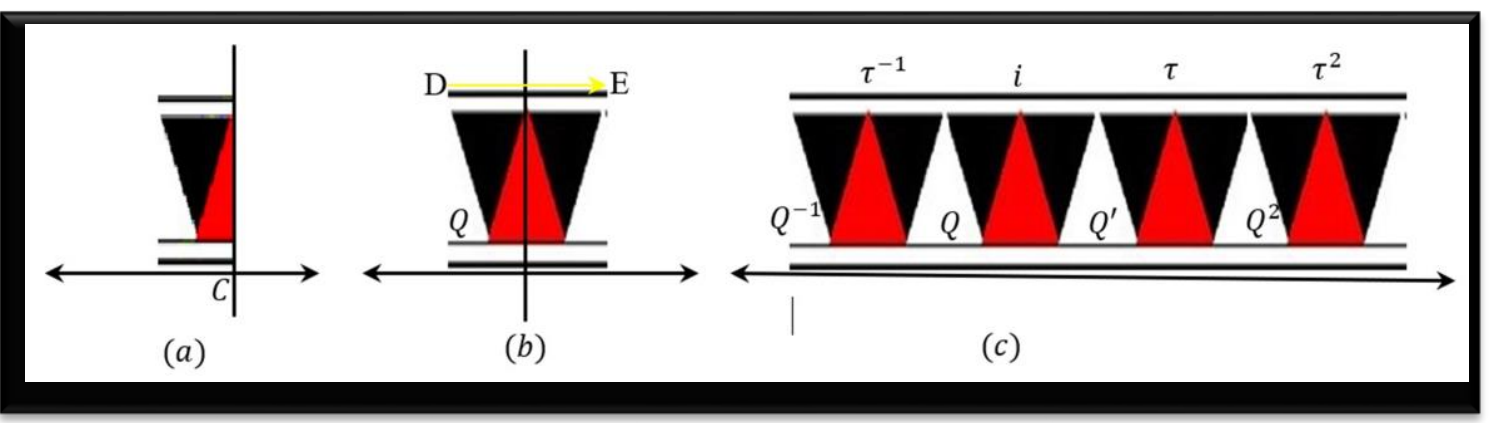

Gambar 6. (a) Motif Dasar Bindu, (b) Motif Pembangun Bindu, (c) Proses Konstruksi Ornamen Bindu

\section{Burangir Eropik}

Burangir Eropik memiliki makna fungsi raja dan namora natoras, segala sesuatu baik itu menyangkut pelaksanaan upacara adat dan ritual harus terlebih dahulu meminta pertimbangan dan ijin kepada raja dan namora natoras. Untuk mengonstruksi ornamen burangir eropik secara matematis, dapat dengan menggunakan konsep geometri

\section{Mosharafa: Jurnal Pendidikan Matematika}


transformasi. Perhatikan pada gambar 7, gambar 7a merupakan motif dasar ornamen burangir eropik, dengan merefleksikan garis $l$, diperoleh motif pembangun ornament burangir eropik sebagaimana diperlihatkan pada gambar 7b. Berdasarkan gambar 7, Misalkan titik $S$ pada bidang motif dasar burangir eropik dan diberikan vektor $\overrightarrow{F G}$ pada bidang motif pembangun burangir eropik, maka $R(S)$ merupakan bayangan dari refleksi motif dasar terhadap garis $l$ dan $T(x)$ merupakan translasi oleh vector $\overrightarrow{F G}$.
Definisikan $R T^{n}(x)$ adalah komposisi refleksi dan translasi, dimana motif dasar burangir eropik di relefksikan terhadap garis $l$, kemudian motif dasar burangir eropik dan bayangannya dilakukan komposisi translasi oleh vektor $\overrightarrow{F G}$. Sehingga diperoleh himpunan $\left\{\ldots R T^{-2}, R T^{-1}, I, R T, R T^{2}, R T^{3}, \ldots\right\}$ yang merupakan sebuah grup yang mengekspresikan ornament burangir eropik.

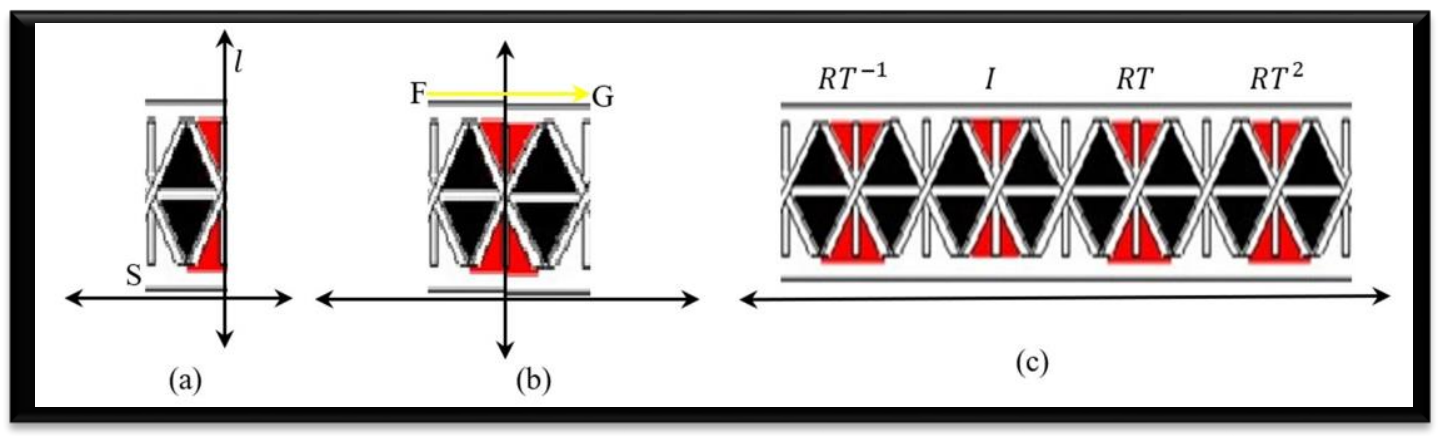

Gambar 7. (a) Motif Dasar Burangir Eropik, (b) Motif Pembangun Burangir Eropik, (c) Konstruksi Ornamen Burangir Eropik.

Dengan demikian, untuk mengonstruksi ornamen burangir eropik secara matematis, terdapat beberapa konsep matematika diantaranya refleksi, translasi, dan komposisi fungsi refleksi dan translasi. Selain itu, terdapat bentuk geometri bidang datar seperti segitiga, belah ketupat, trapesium, dan segi enam.

\section{Pembahasan}

Ornamen-ornamen yang terdapat pada tutup ari bagas godang tersebut mempunyai konsep-konsep matematika yang dapat dibuat sebagai pembelajaran matematika di sekolah. Contohnya Ornamen yang terdapat pada tutup ari bagas godang berbentuk segitiga yang melambangkan dalian na tolu yang artinya tungku yang mempunyai kaki tiga. Secara etimologi merupakan suatu tumpuan yang komponen atau unsurnya terdiri dari tiga, dengan maksud memberi keseimbangan terhadap tungku tersebut. Dalam upacaraupacara adat, ketiga lembaga dalam dalihan na tolu ini memegang peranan yang penting dalam menetapkan 
keputusan-keputusan. Dari segi konsep matematika tutup ari ini adalah segi tiga yang peranannya sangat penting dalam kemasyarakatan. Ibarat sebuah segitiga sama sisi, tentu mempunyai sudut yang sama besarnya dan panjang sisi yang sama dan peranan yang sama pentingnya. Dengan menggunakan masalah kontekstual yang sangat dekat dengan kehidupan siswa, membuat siswa lebih menyukai dengan masalah-masalah yang diberikan. Selain itu, siswa lebih termotivasi dan tertarik untuk menyelesaikan permasalahan yang diberikan.

Pada bagian tutup ari rumah adat bagas godang, memiliki banyak motif-motif atau ornamen yang memiliki makan filosofi diantaranya ornamen bona bulu, bindu atau rusuk robung, dan burangir eropik. Berdasarkan hasil penelitian, diketahui bahwa setiap ornamen dapat dieksplorasi konsep-konsep geometri yang ada pada setiap ornamen. Konsep-konsep ini seperti konsep grup siklis dan konsep geometri transformasi dapat diberikan dan diajarkan kepada siswa kelas sekolah menengah atas bahkan perguruan tinggi. Selain itu, ornamen2 ini juga dapat dijadikan materi bahan ajar untuk siswa level sekolah menengah bahkan sekolah dasar dengan khususnya pada topik geometri bidang datar. Siswa dapat mengenal budaya mereka sekaligus dapat mempelajari konsep-konsep matematika dengan baik.

\section{Penutup}

Ornamen yang ada pada tutup ari bagas godang dan sopo godang berupa garis-garis geometris (garis lurus) menggambarkan benda-benda alam, seperti matahari, bulan dan bintang serta bunga. Fungsi utama dari ornamen tersebut bukan sekadar sebagai hiasan, tetapi berfungsi simbolik untuk menunjukkan banyak hal yang berkaitan dengan nilai budaya dan pandangan hidup masyarakat Mandailing. Bagian-bagian dari bangunan Bagas Godang diberi nama juga mengandung makna simbolik.

Hasil eksplorasi yang ada pada seni bangunan rumah adat Bagas Godang dan ornamen yang ada pada Bagas Godang tersebut diperoleh beberapa konsep matematika diantaranya konsep grup siklis, translasi dan refleksi, vektor, serta beberapa bangun geometri bidang seperti, persegi, persegi panjang, macam-macam segitiga, trapesium, jajargenjang, belah ketupat, dan segi enam beraturan. Konsep matematika yang telah ditemukan masih dapat dieksplorasi dan dimodifikasi dalam bentuk bahan ajar yang di desain dan dikemas secara menarik sehingga dapat diajarkan di dalam kelas.

\section{UCAPAN TERIMA KASIH}

Banggor Patuan dan Bahraini, Tutur Poda Pangalaho ni Partuturon Adat Dalihan Natolu Tapanuli Bahagian Selatan. 


\section{Daftar Pustaka}

Afriansyah, E. A. (2012). Implementasi Pmri dalam Materi Sifat Komutatif dan Assosiatif pada Bilangan Bulat untuk Level Siswa Sd/mi. Mosharafa: Jurnal Pendidikan Matematika, 1(2), 67-72.

Afriansyah, E. A. (2017). Desain Lintasan Pembelajaran Pecahan melalui Pendekatan Realistic Mathematics Education. Mosharafa: Jurnal Pendidikan Matematika, 6(3), 463474.

Harahap, E. M. (2016). Variasi Fonologi dan Leksikon Dialek Angkola Desa Sialagundi di Desa Aek Garugur Kabupaten Tapanuli Selatan. Jurnal Metamorfosa, 2(2).

Hasanuddin, H. (2017). Etnomatematika Melayu: Pertautan Antara Matematika Dan Budaya Pada Masyarakat Melayu Riau. Sosial Budaya, 14(2), 136-149.

Kholilah, A., dkk. (2017). Bentuk Dan Fungsi Rumah Adat Raja Pamusuk Mandailing. Bercadik: Jurnal Pengkajian dan Penciptaan Seni, 2(1).

Kozok, U. (1999). Warisan leluhur: sastra lama dan aksara Batak (Vol. 17). Kepustakaan Populer Gramedia.

Lubis, Z. (2014). Menumbuhkan (Kembali) Kearifan Lokal dalam Pengelolaan Sumberdaya Alam di Tapanuli Selatan. Antropologi Indonesia.

Lubis, S. I., Mujib, A., \& Siregar, H. (2018). Eksplorasi Etnomatematika pada Alat Musik Gordang Sambilan. Edumatika: Jurnal Riset Pendidikan Matematika, 1(2), 1-10.
Mujib, A. (2017). Identifikasi Miskonsepsi Mahasiswa Menggunakan CRI pada Mata Kuliah KalkuluS II. Mosharafa: Jurnal Pendidikan Matematika, 6(2), 181-192.

Mujib, A. (2018, April). Konflik Kognitif dalam Pembelajaran Kalkulus II. Dalam Prosiding Seminar Nasional Hasil Penelitian (Vol. 1, No. 1, pp. 87-96).

Murtiyasa, B. (2010). Strategi Pengembangan Pembelajaran Matematika pada Abad XX.

Nasution, H. \& Pandapotan, S, H. (2005). Adat Budaya Mandailing Dalam Tantangan Zaman, Prov. Sumatera Utara: Forkala.

Nugraha, A., \& Sundayana, R. (2014). Penggunaan Alat Peraga sebagai Upaya untuk Meningkatkan Prestasi Belajar dalam Memahami Konsep Bentuk Aljabar pada Siswa Kelas VIII di SMPN 2 Pasirwangi. Mosharafa: Jurnal Pendidikan Matematika, 3(3), 133142.

Supriadi, M. P. (2013). Pembelajaran Etnomatematika dengan Media Lidi dalam Operasi Perkalian Matematika untuk Meningkatkan Karakter Kreatif dan Cinta Budaya Lokal Mahasiswa PGSD, makalah seminar nasional. Pendidikan Matematika SPS UPI. 